as the number of patients still in the trial and free of any " major cardiac event," expressed as a percentage of the total number in the trial at that point-that is, the number of starters less those removed for non-cardiac complications or lost to follow-up.

At two years the proportion of patients remaining free of major cardiac events is greater for the control group (75\%) than for the two oil groups (olive oil $57 \%$, corn oil $52 \%$ ). The likelihood that the difference between the control and corn-oil groups was due to chance is $0.05-0.1$ (S.E. of difference, $\pm 13 \%)$. Among those patients who were followed for a third year no new trend emerged.

\section{Conclusion}

The aim of the trial was not to duplicate the many carefully regulated laboratory studies of the effects of unsaturated oils on serum cholesterol. Rather was it aimed to study the feasibility and possible value of such regimes in a typical group of hospital coronary patients. Among such persons, and especially where treatment is prolonged, it is inevitable that some will comply incompletely or not at all. We estimated that initially the patients in the two oil groups took on average about $90 \%$ of the prescribed $80 \mathrm{~g} . /$ day ; but after a year the estimated average intake fell to around $60 \%$ of the ideal. As a result the differences in serum-cholesterol levels between the two oil groups are less than would be predicted theoretically, although still highly significant. Such limitations may be unavoidable in a clinical trial of a rather unpleasant regime.

The patients receiving the key treatment (corn oil) fared worse than those in the other two groups: two years from the start of treatment infarction or death had occurred in onequarter more of the corn-oil than of the control group. This difference closely approaches the conventional significance level $(0.1>P>0.05)$. The probability that a true difference of the same magnitude but in the other direction may have been missed by chance is less than 1 in 1,000 . It is concluded that under the circumstances of this trial corn oil cannot be recommended as a treatment of ischaemic heart disease. It is most unlikely to be beneficial, and it is possibly harmful.

\section{Summary}

Eighty patients with ischaemic heart disease were allocated randomly to three treatment groups. The first was a control group. The second received a supplement of olive oil with restriction of animal fat. The third received corn oil with restriction of animal fat. The serum-cholesterol levels fell in the corn-oil group, but by the end of two years the proportions of patients remaining alive and free of reinfarction (fatal or non-fatal) were $75 \%, 57 \%$, and $52 \%$ in the three groups respectively. The likelihood that the worse experience of the patients treated with corn oil was due to chance alone was $0.05-0.1$. The likelihood that the trial failed by chance to detect a true and important benefit from corn oil was extremely remote. It is concluded that under the circumstances of this trial corn oil cannot be recommended in the treatment of ischaemic heart disease.

We are grateful to Professor W. S. Peart for advice and encouragement, to Paddington General Hospital for clinic facilities, and to physicians of St. Mary's and Paddington General Hospitals for referral of patients.

\section{REFERENCES}

Ahrens, E. H., Tsaltas, T. T., Hirsch, J., and Insull, W. (1955). f. clin.

Ball, K. P., McAllen, P. M., Pilkington, T. R. E., Sharland, D. E., Sowry, G. S. C., and Wilkinson, P. (1964). Proc. IV Europ. Congr.

Blackburdiol., H., Keys, A., Simonson, E., Rautaharju, P., and Punsar, S. (1960). Circulation, 21, 1160.

Bronte-Stewart, B., Keys, A., and Brock, J. F. (1955). Lancet, 2, 1103.

Gordon, H., and Brock, J. F. (1958). S. Afr. med. Ұ., 32, 397.

Henly, A. A. (1957). Analyst, 82, 286 .

Kannel, W. B., Dawber, T. R., Kagan, A., Revotskie, N., and Stokes, J. (1961). Ann. intern. Med., 55, 33 .

Keen, H., and Rose, G. A. (1958). Brit. med. 7., 1, 1508.

Keys, A., Kimura, N., Kusukawa, A., Bronte-Stewart, B., Larsen, N.,

and Keys, M. H. (1958). Ann. intern. Med., 48, 83. T. R. E. (1963). Brit. med. 7., 1, 571.

Oliver, M. F., and Boyd, G. S. (1961). Lancet, 2, 499.

Pilkington, T. R. E., Stafford, J. L., Hankin, V., S., Simmonds, F. M., and Koerselman, H. B. (1960). Brit. med. F., 1,' 23.

Rose, G. A. (1962). Bull. W.ld Hith Org., 27, 645 .

Stamler, J., Katz, L. N., Pick, R Lewis, L. A., Page, I H Pick, A Kaplan, B. M., Berkson, D. M., and Century, D. F. (1960). Circulation, 22, 658 .

\title{
Carcinoid Syndrome Associated with Oat-cell Carcinoma of Bronchus
}

\author{
J. D. KINLOCH,* M.B., M.R.C.P.ED., M.R.C.P.GLASG. ; J. N. WEBB, † M.B., B.CHIR., D.OBST.R.C.O.G. ; \\ D. ECCLESTON, $\ddagger$ J. ZEITLIN, $\ddagger$
}

Brit. med. F., 1965, 1, 1533-1535

The remarkable potential of carcinomas of the bronchus to produce endocrine disorders, such as Cushing's syndrome (Brown, 1928), hyponatraemia (Winkler and Crankshaw, 1938), gynaecomastia (Hardy, 1960), and hypercalcaemia (Connor et al., 1956), is now well recognized. The most recent addition to this group of disorders is the carcinoid syndrome, and this is known to be associated with 5-hydroxytryptamine (5-H.T.) secretion (Williams and Azzopardi, 1960) and also with 5-hydroxytryptophan (5-H.T.P.) secretion (Gowenlock et al., 1964). However, 5-H.T. and its metabolites are probably not the direct mediators of carcinoid flushes, and the release of a kinin peptide from the tumour has recently been suggested as responsible (Oates et al., 1964).

We recently had the opportunity to study 5-H.T. metabolism and kinins in a patient with many features of the carcinoid syndrome who was ultimately shown to have an oat-cell carcinoma of the bronchus. As this association has only rarely been recognized and our ignorance of the mechanism responsible for the flushing in the carcinoid syndrome continues, it was thought that our investigations of a single patient would be of sufficient interest to justify a case report.

\section{Case Report}

A bus-conductor aged 43 was admitted to hospital with a history of upper abdominal discomfort, nausea, anorexia, and loss of weight for the previous three months; during the month preceding admis\footnotetext{
- Senior Registrar, Department of Endocrinology and Metabolic Diseases,
Western General Hospital, Edinburgh. †egistrar in Pathology, Western General Hospital, Edinburgh ₹ Research Fellow, Department of Pharmacology, University of Edlaburgh.
} 
sion he had had intermittent aching pain in the right side of his chest spreading into his shoulder and neck. He had smoked 30 cigarettes a day for many years and had a mild "smoker's cough." For a week or two prior to admission his face had been puffy and rather highly coloured; during this period he had collapsed on one occasion on the floor after defaecation, and had then vomited.

Examination showed redness of his face and neck of variable intensity, becoming paler at times, but never clearing completely or extending to the trunk or limbs; there was puffiness around the eyes and fullness of the face, not unlike Cushing's syndrome; and moderate sacral and ankle oedema was present. His liver was palpable 2 in. $(5 \mathrm{~cm}$.) below the subcostal margin and was hard and irregular. Marked hyperperistalsis was audible on direct ascultation, but there was no diarrhoea until shortly before death; barium enema and barium-meal examination revealed no abnormality. No abnormal signs were detected on clinical examination of the chest, but radiography showed an opacity in the right hilum with elevation of the diaphragm.

Blood count, erythrocyte sedimentation rate, and electrolytes were normal, although hypokalaemia (lowest serum potassium $2.4 \mathrm{mEq} / 1$.) developed a month after admission, necessitating potassium supplements. Urinary 17-ketosteroids were 5-6 mg./day and 17-hydroxycorticosteroids were 17-18 mg./day on two estimations. Liverfunction studies showed that the serum alkaline phosphatase was raised to 22 King-Armstrong units and the serum glutamic pyruvic transaminase to 123 units. Liver biopsy showed tumour cells as described below.

The patient's condition steadily deteriorated, and he died two months after admission.

\section{Necropsy Findings}

A small tumour nodule, $2.5 \mathrm{~cm}$. in diameter, of pale grey colour with a dark pink mottling, was ulcerating the wall of the right upper lobe apical bronchus and was infiltrating the surrounding lung, but encroaching little on the bronchial lumen. Metastases were seen in the hilar lymph nodes, in the paratracheal region, and in the anterior mediastinum. Both lungs were congested. There was no evidence of tumour in the intestinal tract, but scarring in the lesser curve of the stomach suggested a healed ulcer. The colon showed marked oedema of the mucosa. Two small tumour nodules were also present in the body and the tail of the pancreas. The liver was grossly enlarged (3,400 g.) and distorted by nodules of tumour. Tumour nodules were also found in the third lumbar vertebral body, in both kidneys, and in the thyroid gland. Histological examination showed the tumour in the lung to be an oat-cell carcinoma arising from a small bronchus, with sheets of small round, oval, or spindle-shaped cells with hyperchromatic nuclei; in some areas, particularly secondary deposits, there was better differentiation, and in others the cells were all of spindle form. Mitotic figures were frequent and a number of giant cells were present. There was considerable haemorrhage and necrosis. The histological features corresponded closely with those described by Azzopardi (1959).

The heart valves and endocardium were normal. The adrenal glands were enlarged (15 g. each) and a small haemorrhagic area was present in the right adrenal cortex. Both adrenal cortices were hyperplastic and consisted almost entirely of compact zona fasciculata cells with only a few atrophied glomerulosa layer cells; microscopic deposits of tumour were present. The renal tubules showed no changes of hypokalaemic nephropathy.

Argentaffin and diazo staining of tumour tissue removed from the liver within half an hour of death was negative. Argyrophil staining, by a modified Bodian's method (Azzopardi and Pollock, 1963), of bronchial, liver, and pancreatic tumour tissue was negative. The sensitivity of the staining method was checked by positive and negative controls. Unstained sections of the same specimens mounted in Univert failed to show auto-fluorescence in ultra-violet light.

\section{Biochemical Investigations}

Methods.-Ten 24-hour urine collections were made before and during treatment and the indolic compounds were determined in aliquots. 5-Hydroxyindole acetic acid (5-H.I.A.A.) was determined by the method of Udenfriend et al. (1955), indole acetic acid (free I.A.A.) by the method of Weissbach et al. (1955), 5-H.T. by the method of Oates (1961), and tryptamine by the method of Hess and
Udenfriend (1959). Total 5-hydroxyindoles were measured in whole blood by the method of Ashcroft et al. (1964), and 5-H.T.P. and 5-H.I.A.A. in blood and tumour by the method of Ashcroft et al. (1965).

The kinin content of heparinized venous whole blood was estimated by a modification (J. Z.) of the methods used by Brocklehurst and Lahiri (1962) and by Gaddum and Horton (1959).

\section{Results}

The results of the estimation of indolic compounds in the urine and the response to treatment are summarized in the Table.

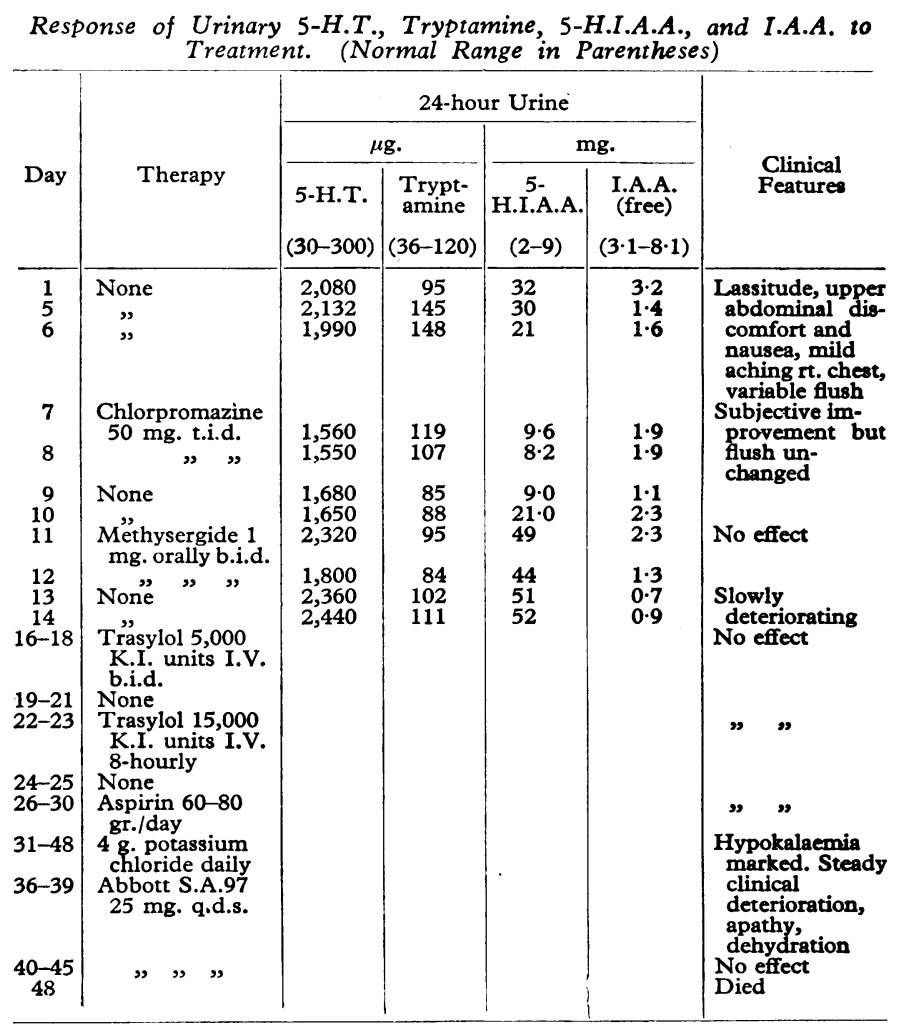

The 5-H.I. level in whole venous blood was raised to $415 \mathrm{~m} \mu \mathrm{g} . /$ $\mathrm{ml}$. (normal range $60-120 \mathrm{~m} \mu \mathrm{g} . / \mathrm{ml}$ ) when the flushing was mild, and to $820 \mathrm{~m} \mu \mathrm{g} . / \mathrm{ml}$. when intense. The 5-H.I.A.A. was 65 mug./ml. (normal value nil). No 5-H.T.P. was detected. These estimations were made prior to treatment. 5-H.T. was found in a concentration of $1.4 \mu \mathrm{g} . / \mathrm{g}$. in the liver metastasis, but no 5-H.T.P. or 5-H.I.A.A. was detected. The lung and pancreas tumour tissue examined contained no 5-H.T., 5-H.T.P., or 5-H.I.A.A.

The only biochemical alteration demonstrated with treatment was a fall in the urinary 5-H.T. excretion on the administration of chlorpromazine. The apparent fall in the 5-H.I.A.A. is an artifact due to interference with the colour reaction by chlorpromazine.

The kinin content of venous whole blood before drug therapy was $25 \mathrm{~m} \mu \mathrm{g} . / \mathrm{ml}$. equivalent of standard bradykinin (normal less than $0.4 \mathrm{~m} \mu \mathrm{g} . / \mathrm{ml}$.). The P.C.V. was $42 \%$, making the kinin content of the plasma $43.1 \mathrm{~m} / \mathrm{g} . / \mathrm{ml}$. equivalent of bradykinin (normal less than $0.7 \mathrm{~m} / \mathrm{g} . / \mathrm{ml}$.). Control experiments showed that the activity measured was bradykinin-like and could not have been due to 5-H.T. or histamine or substance $\mathrm{P}$ as has been suggested (Lancet, 1964).

\section{Effects of Therapy}

An attempt was made to alleviate the patient's symptoms by short courses of potentially effective drugs, and the response of the clinical signs and changes in the excretion of the urinary metabolites of tryptophan were observed.

Although its exact mode of action is unknown, chlorpromazine is said to reduce 5-H.T. turnover in the brain (Gey and Pletscher, 1962), but this may be due to the hypothermia induced (Bartlet, 
1965). An anti-bradykinin effect is also described (Spector and Willoughby, 1963a), and in addition its well-known antiemetic and tranquillizing effect might have been expected to provide some relief. In this patient the nausea and abdominal discomfort were lessened, but there was no change in the facial appearance and the flush. The fall in 5-H.T. excretion was probably a genuine response to the drug, but needs further confirmation in other cases. As mentioned above, the fall in 5-H.I.A.A. is an artifact.

Methysergide (Deseril), a potent inhibitor of 5-H.T. (Doepfner and Cerletti, 1958), showed no effect clinically or chemically.

Oates et al. (1964) have shown that bradykinin, a kinin peptide formed by the proteolytic action of kallikrein on plasma $\alpha 2$-globulin, could induce the characteristic flush in carcinoid patients. Trasylol, an inhibitor of kallikrein and other proteolytic enzymes, was discovered by Frey et al. (1950). It was used by Frey (1953-4) in the treatment of acute pancreatitis on account of its trypsin-inactivating effect, and has been used extensively since then with promising results (Maurer, 1961). It seemed reasonable to see if inhibition of kallikrein and hence bradykinin formation would produce any beneficial effect. No clinical improvement occurred, however.

Homochlorcyclizine, which has been shown to have an antihistamine and antiserotonin action, and inhibits slow release substance in animals (Kimura et al., 1960), had no clinical effect; nor had aspirin, which also has an inhibitory effect on kinins and slow release substance in animals (Collier, 1963; Spector and Willoughby, 1963b).

\section{Discussion}

The facial flush, oedema, and hyperperistalsis together suggested the diagnosis of the carcinoid syndrome, and this was confirmed by the raised blood levels of 5-H.T. and kinins, and the increased urinary excretion of 5-H.T. and 5-H.I.A.A. Radiological examination of the chest suggested that the primary tumour might be in the lung, and at necropsy an oat-cell carcinoma was found in the right upper lobe apical bronchus, and this was thought to be the primary lesion; there were multiple secondary deposits in the liver. 5-H.T. was found in small amounts in the liver metastases only.

Despite the presence of tumour tissue in the liver containing 5-H.T. and the relatively high blood levels of 5-H.T., there were no fibrotic lesions in the heart or other organs, as have been described in the carcinoid syndrome, and which have recently been reviewed by Hallén (1964). It may be that the rapid downhill course of this patient did not permit time for the deposition of the characteristic fibrous plaques on the heart and great vessels.

The hypokalaemia noted, together with the hyperplasia of the adrenal cortex, suggested the possibility that the tumour was producing a substance with corticotrophin-like activity, as described by Holub and Katz (1961) and by Meador et al. (1962). Apart from the facies and hypokalaemia, however, there are no grounds for postulating persistent adrenocortical overactivity.

Treatment with a series of drugs had no clinical effect and only slight biochemical changes were noted with one drug, chlorpromazine; no attempt was made to detect alterations in blood kinin levels. It must be concluded that 5-H.T. and kinin antagonists in the dosage given were of no value in this patient, and their administration did not throw further light on the cause of the carcinoid flush, as might have been hoped.

\section{Summary}

The case of a patient with the carcinoid syndrome is described in which there was an associated oat-cell carcinoma of the bronchus.

Antagonists to 5-H.T. and kinin peptides were administered with no demonstrable effect, except some subjective improvement and a slight fall in the 5-H.T. urinary excretion during chlorpromazine administration.

We are grateful to Dr. J. Strong and Dr. G. W. Ashcroft for their help and advice with the case report. Homochlorcyclizine (S.A.97) was supplied by Abbott Laboratories.

\section{REFERENCES}

Ashcroft, G. W., Crawford, T. B. B., Binns, J. K., and MacDougall, E. J. (1964).' Clin. chim. Acta, 9, 364.

Eccleston, D., and Crawford, T. B. B. (1965). F. Neurochem. In

press.
Azzopardi, J. G. (1959). f. Path. Bact., 78, 513.

and Pollock, D. J. (1963). Ibid., 86, 443.

Bartlet, A. L. (1965). Brit. F. Pharmacol. In press.

Brocklehurst, W. E., and Lahiri, S. C. (1962). F. Physiol. (Lond.), 160, $15 P$

Brown, W. H. (1928). Lancet, 2, 1022.

Collier, H. O. J. (1963). Salicylates, edited by A. St. J. Dixon, B. K. Martin, M. J. H. Smith, and P. H. N. Wood, p. 120. Churchill,

Connor, T. B., Thomas, W. C., and Howard, J. E. (1956). F. clin. Invest., 35, 697.

Doepfner, W., and Cerletti, A. (1958). Int. Arch. Allergy, 12, 89.

Frey, E. K. (1953-4). Therapiewoche, 4, 323.

Kraut, H., and Werle, E. (1950), Kallikrein. Ferd. Enke, Stuttgart.

Gaddum, J. H., and Horton, E. W. (1959). Brit. F. Pharmacol., 14, 117.

Gey, K. F., and Pletscher, A. (1962). Nature (Lond.), 194, 387.

Gowenlock, A. H., Platt, D. S., Campbell, A. C. P., and Wormsley, K. G.' (1964).' Lancet, 1, 304.

Hallén, A. (1964). Ibid., 1, 746.

Hardy, J. D. (1960). F. Amer. med. Ass., 173, 1462.

Hess, S. M., and Udenfriend, S. (1959).' F. Pharmacol. exp. Ther., 127, Holub, $\dot{D}$

D. A., and Katz, F. H. (1961). Clin. Res. Proc., 9, 194

Kimura, E. T., Young, P. R., and Richards, R. K. (1960). F. Allergy, 31, 237.

Lancet, 1964, 1, 539

Maurer, G. (1961). Med. Press, 246, 287.

Meador, C. K., Liddle, G. W., Island, D. P., Nicholson, W. E., Lucas, C. P., Nuckton, J. G., and Luetscher, J. A. (1962). ł. clin. Endocr., 22, 693 .

Oates, J. A. (1961). Methods in Medical Research, edited by J. H. Quastel, p. 169. Year Book Medical Publishers, Chicago.

Melmon, K., Sjoerdsma, A., Gillespie, L., and Mason, D. T. (1964). Lancet, 1, 514.

Spector, W. G., and Willoughby, D. A. (1963a). F. Path. Bact., 86, 487. (1963b). Salicylates, edited by A. St. J. Dixon, B. K. Martin,

M. J. H. Smith, and P. H. N. Wood, p. 141. Churchill, London.
Udenfriend, S., Titus, E., and Wiessbach, H. (1955). J. biol. Chem., 216, 499.

Weissbach, H., King, W., Sjoerdsma, A., and Udenfriend, S. (1959). Ibid., 234, 81.

Williams, E. D., and Azzopardi, J. G. (1960). Thorax, 15, 30.

Winkler, A. W., and Crankshaw, O. F. (1938). F. clin. Invest., 17, 1. 